\title{
Synthesis, spectroscopic
}

characterization and antimicrobial

activities of $N$-methyl-o-

methoxybenzohydroxamic acid and its metal ( $\mathrm{Fe}, \mathrm{Co}, \mathrm{Ni}, \mathrm{Zn})$ complexes

\author{
Saifullah ${ }^{*}$, Naqeebullah Khan ${ }^{1}$, Samiullah ${ }^{1}$, Irshad Ali ${ }^{1}$, Nizamud \\ Din Baloch ${ }^{1}$, Waheed Ahmed Shah ${ }^{1}$ and Abdul Ghaffar ${ }^{1}$ \\ 1. Chemistry Department, University of Balochistan, Quetta 87300-Pakistan \\ *Corresponding author's email: channalsaif@gmail.com
}

Citation

Saifullah, Naqeebullah Khan, Samiullah, Irshad Ali, Nizamud Din Baloch, Waheed Ahmed Shah and Abdul Ghaffar. Synthesis, spectroscopic characterization and antimicrobial activities of $N$-methyl-omethoxybenzohydroxamic acid and its metal (Fe, Co, Ni, Zn) complexes. Pure and Applied Biology. Vol. 10, Issue 1, pp225-233. http://dx.doi.org/10.19045/bspab.2021.100023

\begin{tabular}{llll}
\hline \hline Received: 13/06/2020 & Revised: 22/08/2020 & Accepted: 25/08/2020 & Online First: 15/09/2020 \\
\hline \hline
\end{tabular}

\section{Abstract}

A reportedly synthesized ligand, $N$-methyl-o- methoxybenzohydroxamic acid (Nmombha), and its freshly prepared transition metal (Iron, Cobalt, Nickel, and Zinc) complexes have been synthesized. For characterization of reportedly synthesized ligand and its freshly prepared coordination compounds, spectroscopic techniques like Fourier transform infrared and ultraviolet/visible spectroscopy have been used. Spectroscopic studies show that the ligand acts as a bidentate chelate which forms a ring-like structure. The coordination of synthesized ligand with transition metals is via $O, O$ donor sites, and it forms a fivemembered chelating ring on complex formation. Antimicrobial activities such as antibacterial and antifungal activities have been done for the said ligand and its complexes. Antibacterial activity of the synthesized ligand and its metal complexes are examined against four different species of Gram-positive and Gram-negative bacterial strains including Staphylococcusaureus, Klebsieludla, Esherichia coli, and Pseudomonas. Comparing the antibacterial effectiveness, the metal complexes having greater lipophilicity character show much higher antibacterial efficiency when compared with the free ligand. Cytotoxicity evaluation of the compounds shows that some of the samples are highly cytotoxic.

Keywords: Brine shrimp lethality; FT-IR; Hydroxamic acid; Metal complexes

Introduction

Hydroxamic acids are synthetic organic compounds or naturally occurring compounds and can produce ions very easily. They consist of two groups, oxime $(-\mathrm{N}-\mathrm{OH})$ and the carbonyl group and are generally called "N-hydroxy amides" [1, 2]. Most of the biochemists are interested with hydroxamic acids due to their important biological activities. These activities are due to chelate formation with metal ions because they can form chelates, especially with transition metals. The ligands are in keto form in most of the metal-hydroxamic acid such as iron, cobalt, nickel, and zinc. These coordinate through O, O-donor sites [3]. Several synthetic procedures are reported in the 
literature for the ligand synthesis, [4-7] but mostly the methods are time-consuming, expensive, and tiresome. Therefore, they are generally prepared by the reaction of hydroxylamine with esters (RCOOR) or acid chlorides (RCOCl) [8-10]. These acids can act as anti-tumor, antituberculosis, anti-cancer, anti-malarial, anti-fungal, anti-allergic, and hypotensive agents $[11,12]$. For specific enzymes like matrix metalloproteinanses, histonedeacetylases, ureases [13], and peroxidases [14], these acids act as effective and selective enzyme inhibitors.

Transition metals show variable oxidation numbers and can react with several electronegative elements [15]. These metals have been utilized in many drugs resulting in enhanced therapeutic and pharmacological properties, such as antiinflammation, anti-microbial [16], and anti-cancer [17]. The transition metals are the best catalysts and can act as important catalysts in photochemistry and material synthesis. They show different magnetic, chemical, and optical properties [18].

In this work, we have synthesized coordination compounds of following metals Co (II), Fe (III), Zn (II) and Ni (II) from a reportedly synthesized ligand, $\mathrm{N}$ methyl-o- methoxybenzohydroxamic acid, and the characterization of coordination compounds have been done by FT-IR and UV/VIS spectroscopy. Anti-bacterial, anti- tumor, and anti-fungal activities have been tested as well.

\section{Materials and Methods}

The materials were used without any purification because all materials were of analytical grade (Sigma-Aldrich). The purity of synthesized ligand and its TMCs were tested by TLC. KBr pellets were used to record the IR spectrum on the FTIR spectrophotometer. UV/VIS spectrum was recorded in dimethylsulfoxide (DMSO) with UV/VIS spectroscopy (Shimadzu UV/VIS, 1700).

\section{Preparation/synthesis of N-methyl-o-} methoxybenzohydroxamic acid

For the preparation of N-methyl-omethoxybenzohydroxamic acid, the compound $o$-Methoxybenzoyl chloride (4.3 g, $25 \mathrm{mmol}$ ) was added dropwise in a mixture which was ice-cooled containing $\mathrm{N}$-methylhydroxylamine hydrochloride $(2.1 \mathrm{~g}, 25 \mathrm{mmol})$ in ethanol $(100 \mathrm{~mL})$ and sodium bicarbonate $(4.2 \mathrm{~g}, 50 \mathrm{mmol})$ as well, and continuously stirred for 30 minutes. The filtration was done carefully, and at very minimum pressure evaporation was proceeded. The obtained mass was put in boiled EtOAc (ethyl acetate, $50 \mathrm{~mL}$ ) and filtration was done for the removal of undesired solid mass. On cooling the precipitation of ligand starts and the whole night it was kept in the refrigerator to form more and more crystals. The pure crystals of ligand were dried over silica. Ligand preparation is shown in (Scheme 1).

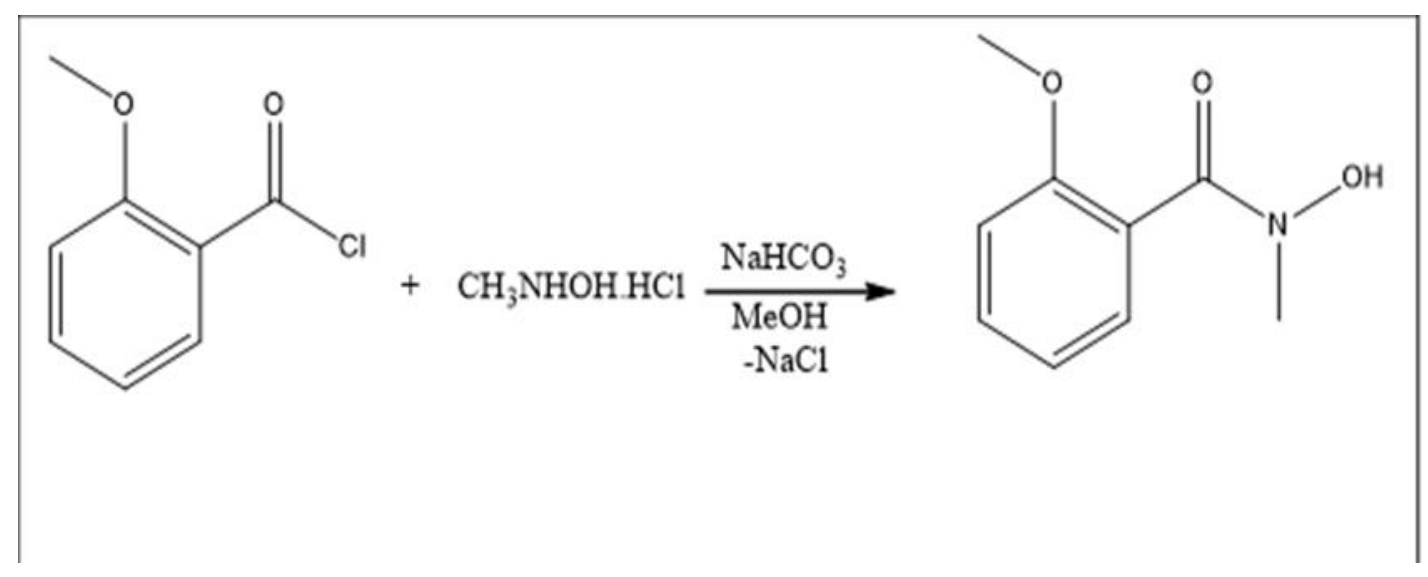

Scheme 1. Synthesis of N-methyl-o-methoxybenzohydroxamic acid Synthesis of metal complexes 
TMCs were synthesized by mixing an equivalent mixture of the ligand with potassium hydroxide and were stirred for 15 minutes at room temperature in methanol. A freshly prepared aqueous solution of metal salts of transition elements ( $\mathrm{Fe}, \mathrm{Co}, \mathrm{Ni}$, and $\mathrm{Zn}$ ) was added ligand and its metal salts was maintained 2:1 respectively. Through filtration, the solid products were collected and washed with distilled water, methanol, petroleum ether, and finally dried. The synthetic method for complexes is given below in (Scheme 2).

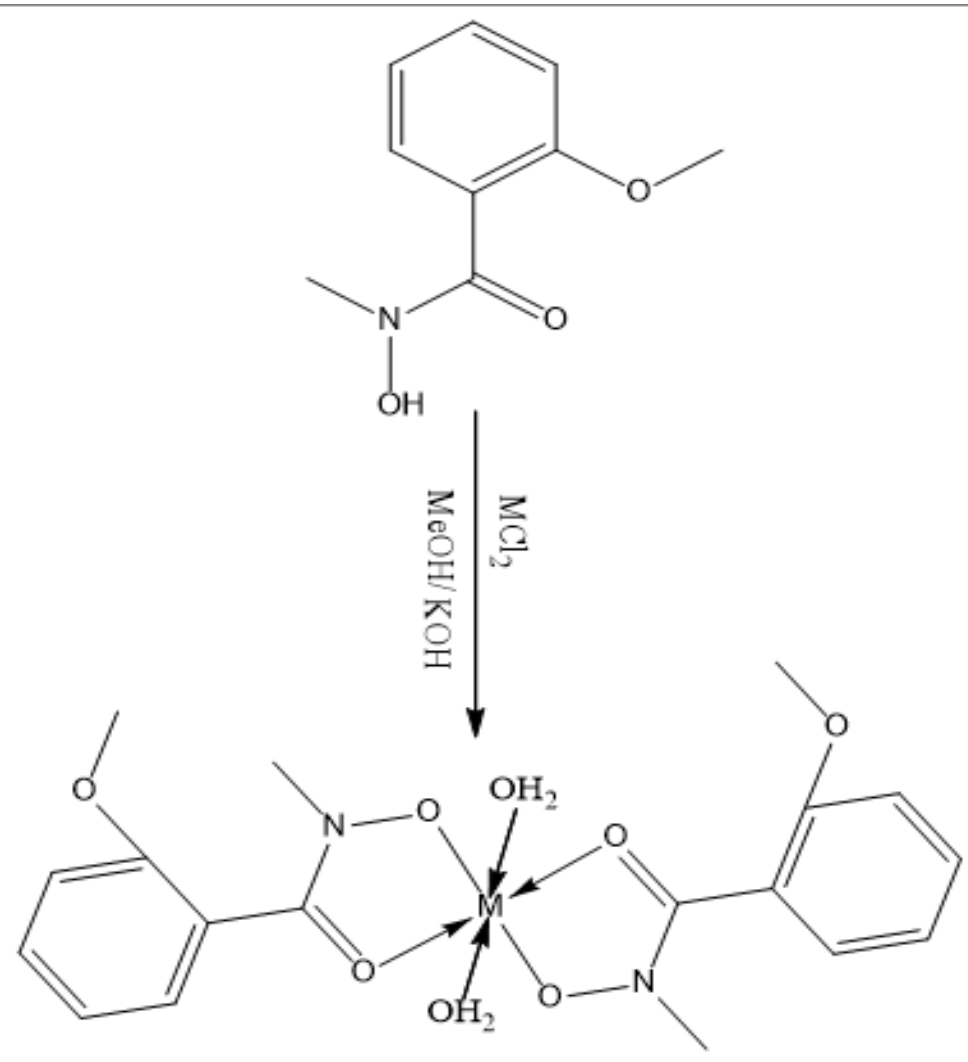

and stirred for two hours. The ratio of

Scheme 2. Synthesis of comples of N-methyl-o-methoxybenzohydroxamic acid with tyransition metals

\section{Result and Discussion \\ Synthesis}

The preparation of bidentate ligand $N$ methyl-o-methoxybenzohydroxamic acid was done via nucleophilic substitution of $o$-methoxy benzoyl chloride with $\mathrm{N}$ methylhydroxylamine hydrochloride in the presence of a weak base such as sodium bicarbonate. Coordination compounds were prepared by the reaction of reportedly synthesized ligand with $\mathrm{ML}_{2} \mathrm{Fe}$ (II), Co (II), Zn (II), and Ni (II) in the presence of $\mathrm{KOH}$ in methanol. TLC was used to assure the purity of synthesized ligand and its coordination compounds.
The physical characteristics of the reportedly synthesized ligand and its TMCs are given below in (Table 1).

\section{Infrared spectroscopy}

The range maintained for IR spectra of reportedly synthesized ligand and its coordination compounds were in between $4000-400 \mathrm{~cm}^{-1}$ in the solid-state. The value of absorption bands is given below in (Table 2). The main stretching vibrations in the reportedly synthesized ligand are $v(\mathrm{OH}), v(\mathrm{C}=\mathrm{O}), v(\mathrm{C}-\mathrm{N})$, and $v(\mathrm{~N}-\mathrm{O})$ which are observed at $3123 \mathrm{~cm}^{-1}, 1610 \mathrm{~cm}^{-1}, 1440$ $\mathrm{cm}^{-1}$, and $917 \mathrm{~cm}^{-1}$, respectively. The broadband for $v(\mathrm{OH})$ in the range of 3123 
$\mathrm{cm}^{-1}$ shows the existence of intermolecular hydrogen bonding in the ligand. The other important band for $v(\mathrm{C}=\mathrm{O})$ in the range of $1610 \mathrm{~cm}^{-1}$ is found remarkably lower than the ketonic range $\left(1650 \mathrm{~cm}^{-1}\right)$, which indicates the existence of ligand in the ketonic form [19, 20].

Table 1. Physical data of synthesized ligand and its TMCs

\begin{tabular}{|c|c|c|}
\hline Compounds & State & Yield (\%) \\
\hline Nmombha & Colorless crystals & $85 \%$ \\
\hline $\boldsymbol{F e}(\text { Nmombha })_{2}$ & Reddish-brown & $61 \%$ \\
\hline $\boldsymbol{C o}(\text { Nmombha })_{2}$ & Pink solid & $75 \%$ \\
\hline $\boldsymbol{N i}(\text { Nmombha })_{2}$ & Light green & $72 \%$ \\
\hline $\mathbf{Z n}(\text { Nmombha })_{2}$ & Colorless & $77 \%$ \\
\hline
\end{tabular}

Table 2. Infrared data for ligand and its transition metal complexes

\begin{tabular}{|c|c|c|c|c|c|}
\hline Compounds & $\begin{array}{c}\boldsymbol{v}(\boldsymbol{O H}) \\
\boldsymbol{c m}^{-1}\end{array}$ & $\begin{array}{c}\boldsymbol{v}(\boldsymbol{C = O}) \\
\boldsymbol{c m}^{-1}\end{array}$ & $\begin{array}{c}\boldsymbol{v}(\boldsymbol{C}-\boldsymbol{N}) \\
\boldsymbol{c m}^{-1}\end{array}$ & $\begin{array}{c}\boldsymbol{v}(\boldsymbol{N O}) \\
\boldsymbol{c m}^{-1}\end{array}$ & $\begin{array}{c}\boldsymbol{v}(\boldsymbol{M O}) \\
\boldsymbol{c m}^{-1}\end{array}$ \\
\hline Nmombha & 3123 & 1609 & 1440 & 917 & ---- \\
\hline $\boldsymbol{F e}(\text { Nmombha })_{2}$ & ---- & 1587 & 1463 & 957 & 548 \\
\hline $\boldsymbol{C o}(\text { Nmombha })_{2}$ & ---- & 1595 & 1469 & 942 & 523 \\
\hline Ni $(\text { Nmombha })_{2}$ & ---- & 1602 & 1436 & 941 & 518 \\
\hline Zn $(\text { Nmombha })_{2}$ & ---- & 1598 & 1482 & 956 & 511 \\
\hline
\end{tabular}

In the IR spectra of complexes, the most important characteristic is the absence of a broad absorption band of $v(\mathrm{O}-\mathrm{H})$ at 3123 $\mathrm{cm}^{-1}$. The disappearance of the broad absorption band of the $v(\mathrm{O}-\mathrm{H})$ group present in the spectra of ligand shows the formation of metal complexes and it is easily recognized by observing the absence $v(\mathrm{O}-\mathrm{H})$ peak. Therefore, it is interpreted that on complexation the proton of the hydroxyl group has been replaced by metal ions. It also indicates that in metal complexes, the ligand is present in the deprotonated form. The carbonyl group $v(\mathrm{C}=\mathrm{O})$ appears in the range of 1602-1587 $\mathrm{cm}^{-1}$ in the spectra of complexes. The lower range existence of $v(\mathrm{C}=\mathrm{O})$ vibrations in spectra of complexes as compared to ligand suggests the coordination of ligand through the oxygen of carbonyl group upon complexation. The existence of carbonyl group in the lower range as compared to normal ketonic peak and the absence of $v(\mathrm{O}-\mathrm{H})$ vibration indicates the bidentate nature of ligand and existence of a five-membered chelating ring on complex formation. The IR peaks in the range of $1482-1436 \mathrm{~cm}^{-1}$ show the existence of $v(\mathrm{C}-\mathrm{N})$ bond. Strong absorption band occurring in the range of 957-941 $\mathrm{cm}^{-1}$ in spectra of complexes indicates the existence of $v(\mathrm{~N}-\mathrm{O})$ stretching vibrations. In the region 3500 to $3300 \mathrm{~cm}^{-1}$, the appearance of broadband along with a characteristic peak in the range 760 to $723 \mathrm{~cm}^{-1}$ in spectra of complexes suggests the coordination of water molecules with metal ions and six coordinated geometry around metals.

The appearance of very weak and short bands in the lower energy range is because of ground level (lower) energy vibrations that show the formation of metal-oxygen bonds (M-O). These $\mathrm{M}-\mathrm{O}$ stretching vibrations appearing in spectra of complexes at $548 \mathrm{~cm}^{-1}, 522 \mathrm{~cm}^{-1}, 518 \mathrm{~cm}^{-}$ $1,511 \mathrm{~cm}^{-1}$ have been assigned to $\mathrm{M}-\mathrm{O}$ bonds of $\mathrm{Fe}$ (Nmombha), Co (Nmombha), $\mathrm{Ni}$ (Nmombha) 2 and $\mathrm{Zn}$ (Nmombha), respectively. This strongly supports the formation of transition metal hydroxamates [21, 22].

\section{Ultraviolet spectroscopy}

Visible ultraviolet spectroscopy (UV-Vis or UV/Vis) or ultraviolet spectrophotometer mainly refers to 
absorption or emission (reflection) spectroscopy in some of the ultraviolet and nearby spectral regions. It is revealed from the above statement that this spectrophotometer uses light in the visible and nearby ranges. In the visible region absorption or reflection directly affects the apparent color of the chemicals which is involved. In this range, excitation occurs in atoms and molecules. In absorption spectroscopy, the transition or excitation is from the ground state to the excited state, while it is reverse of fluorescence spectroscopy where the transition occurs from an excited state to the ground state. Therefore, these two spectroscopic techniques are complementary to each other [23].

The Ultraviolet absorbance of synthesized ligand and its freshly prepared complexes is studied for the first time. UV-Vis spectroscopy is carried out to observe the change in the electronic transition of ligands and its metal complexes. Dimethylsulfoxide (DMSO) was used to make the solutions of ligands and their complexes. The concentration for the complexes was kept $0.0001 \mathrm{M}$ and 0.001 $M$. The wavelength was in the range of 200-400 nm.

In the electronic spectrum of synthesized ligand (Nmombha) a band with $\lambda \max$ is obtained at $357.5 \mathrm{~nm}$ wavelength. This is ascribed to the $\pi-\pi^{*}$ transition of ligand electrons whereas, in the spectra of complexes, a shift of 77-101 nm wavelength is observed in spectra of complexes that confirm the formation of complexes.

In the spectrum of complex $\mathrm{Fe}$ (II), an absorption band at $431 \mathrm{~nm}$ is observed which may be ascribed to the d-d transition of electrons in metal complexes.

\section{Antifungal activity}

The in vitro antifungal activity of prepared/synthesized ligand and its freshly prepared coordination compounds have been performed by Agar Tube Dilution Protocol. Synthesized compound was tested against microorganisms such as
Candida glabarata, Candida albicans, Trichophyton, Aspergillus niger, Microsporum canis, and Fusarium lini. In Petri plates using nutrient agar medium test organisms were grown. The synthesized ligand and its transition metal complexes were dissolved in DMSO. The concentration of compounds was $200 \mathrm{~g} / \mathrm{ml}$. The incubation of all plates was done at 27 degrees Centigrade for 7-10 days. The antifungal assay of synthesized ligand and its complexes were measured by MIC (minimum inhibitory concentration) [24].

The in vitro antifungal bioassay of synthesized ligand and its freshly prepared transition metal complexes have shown negligible and insignificant activity. The percent inhibition of ligand and its complexes is found $0 \%$.

\section{Brine shrimp lethality test (Cytotoxicity} evaluation)

Brine shrimp lethality assay [25-27] is an easy, simplest one, low cost, a fast, and comprehensive assay that is commonly used for natural and synthetic origin of bioactive compounds. The pure compounds, metal complexes product extracts, and fractions can be tested for their bioactivity. It has advantages of being inexpensive, simple, and rapid. Commonly, this test is done for analysis of the cytotoxic effect of bioactive chemicals. It is a basic test for heavy metals [28] plant extracts, fungal toxins, cyanobacteria toxins, and cytotoxicity of dental material [29].

Brine shrimp lethality was first developed by Michael et al, in 1956. Further work was done by others. This assay has successfully used as a bioassay guide for antitumor agents and cytotoxic activity in 1982.

Cytotoxicity of already prepared/synthesized ligand and its freshly prepared metal complexes were assessed by using cytotoxic evaluation tests according to the Michael et al, method [30]. Thirty shrimps were used to each of all test tubes of hydroxamic acid and its 
complexes. After 24 hours, the mortality of brine shrimps was observed.

Some of the samples were highly cytotoxic and some of them show cytotoxicity at higher concentrations.
The results that were obtained from brine shrimp lethality are represented below in (Table 3).

Table 3. Brine shrimp lethality assay of hydroxamic acid and its metal complexes

\begin{tabular}{|c|c|c|c|c|c|c|}
\hline Test samples & $\begin{array}{c}\text { Dose } \\
(\mu \mathrm{gg} / \mathrm{ml})\end{array}$ & $\begin{array}{c}\text { No. of } \\
\text { Shrimps }\end{array}$ & $\begin{array}{c}\text { No. of } \\
\text { Survivors }\end{array}$ & $\begin{array}{c}\% \\
\text { Mortality }\end{array}$ & $\begin{array}{c}\text { STD. } \\
\text { Drugs }\end{array}$ & $\begin{array}{c}\% \\
\text { Mortality }\end{array}$ \\
\hline Nmombha & 10 & 30 & 01 & $96.66 \%$ & $/ /$ & $/ /$ \\
\hline $\boldsymbol{F e}\left(\right.$ Nmombha $_{2}\left(\mathrm{OH}_{2}\right)_{2}$ & 10 & 30 & 25 & $16.66 \%$ & $\begin{array}{c}\text { Etopos- } \\
\text { side }\end{array}$ & $46.66 \%$ \\
\hline $\boldsymbol{C o}(\text { Nmombha })_{2}$ & 10 & 30 & 05 & $83.33 \%$ & $/ /$ & $/ /$ \\
\hline $\mathbf{Z n}(\text { Nmombha })_{2}$ & 10 & 30 & 01 & $96.66 \%$ & $/ /$ & $/ /$ \\
\hline
\end{tabular}

\section{Antibacterial activity}

Hydroxamic acid and its metal complexes were checked for antibacterial activity through the Agar well method [31]. 5mm cork borer has been used. The fresh strain of micro-organisms was cultured on MHA media, the lawn was formed through sterile swab on MHA media. All the samples were poured into the wells through micro-pipater. The ligand and its complexes were checked for antibacterial activity against Gram-negative bacteria (Pseudomonas, Klebsiella E. coli) and Gram-positive (S.aureus). The tests of ligand and its TMCs revealed that the

Table 4. Antibacterial tests of already reported/synthesized ligand and its metal complexes

\begin{tabular}{|c|c|c|c|c|c|}
\hline Organism & \multicolumn{5}{|c|}{ Sample labels } \\
\hline & $\mathrm{Co}(\mathrm{Nmombha})_{2}$ & $\mathrm{Fe}(\mathrm{Nmombha})_{2}$ & $\mathrm{Zn}(\mathrm{Nmombha})_{2}$ & $\mathrm{Ni}(\mathrm{Nmombha})_{2}$ & Nmombha \\
\hline E-coli & $13 \mathrm{~mm}$ & $14 \mathrm{~mm}$ & $28 \mathrm{~mm}$ & $11 \mathrm{~mm}$ & $13 \mathrm{~mm}$ \\
\hline S-aureus & $13 \mathrm{~mm}$ & Nil & $20 \mathrm{~mm}$ & 15 & Nil \\
\hline Klebsiella & $7 \mathrm{~mm}$ & Nil & $9 \mathrm{~mm}$ & Nil & $7 \mathrm{~mm}$ \\
\hline Pseudomonas & 24 & Nil & $11 \mathrm{~mm}$ & $12 \mathrm{~mm}$ & $7 \mathrm{~mm}$ \\
\hline
\end{tabular}
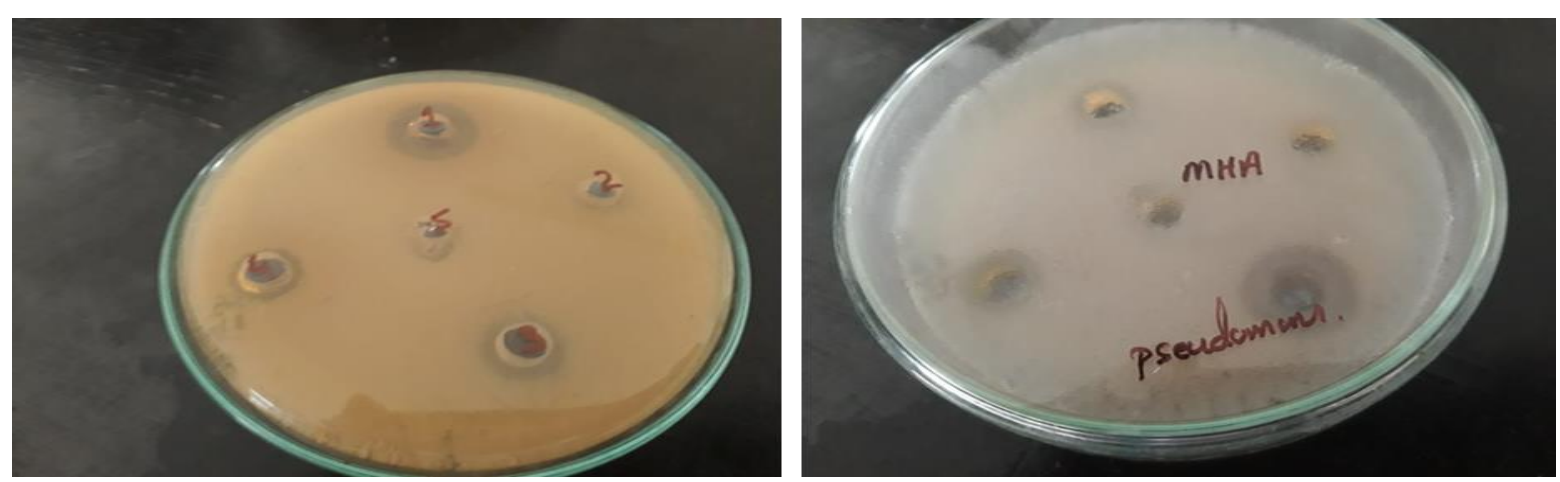

Figure 1. Antibacterial activity of N-methyl-o methoxybenzohroxamic acid and its metal complexes against Pseudomonas transition metals have high activity than the ligand. Mostly, the ligand and its metal complexes are found to inhibit approximately all tested bacterial strains (Table 4 \& Fig. 1-4). The enhanced antimicrobial activity of ligand and TMCs are related to their chelation property that enhances the lipophilicity of complexes which results in growth inhibition of the bacterial strains [32-34].

Among all the metal complexes, the higher antibacterial activity was shown by $\mathrm{Zn}$ (II) complex that may be due to its higher stability. 

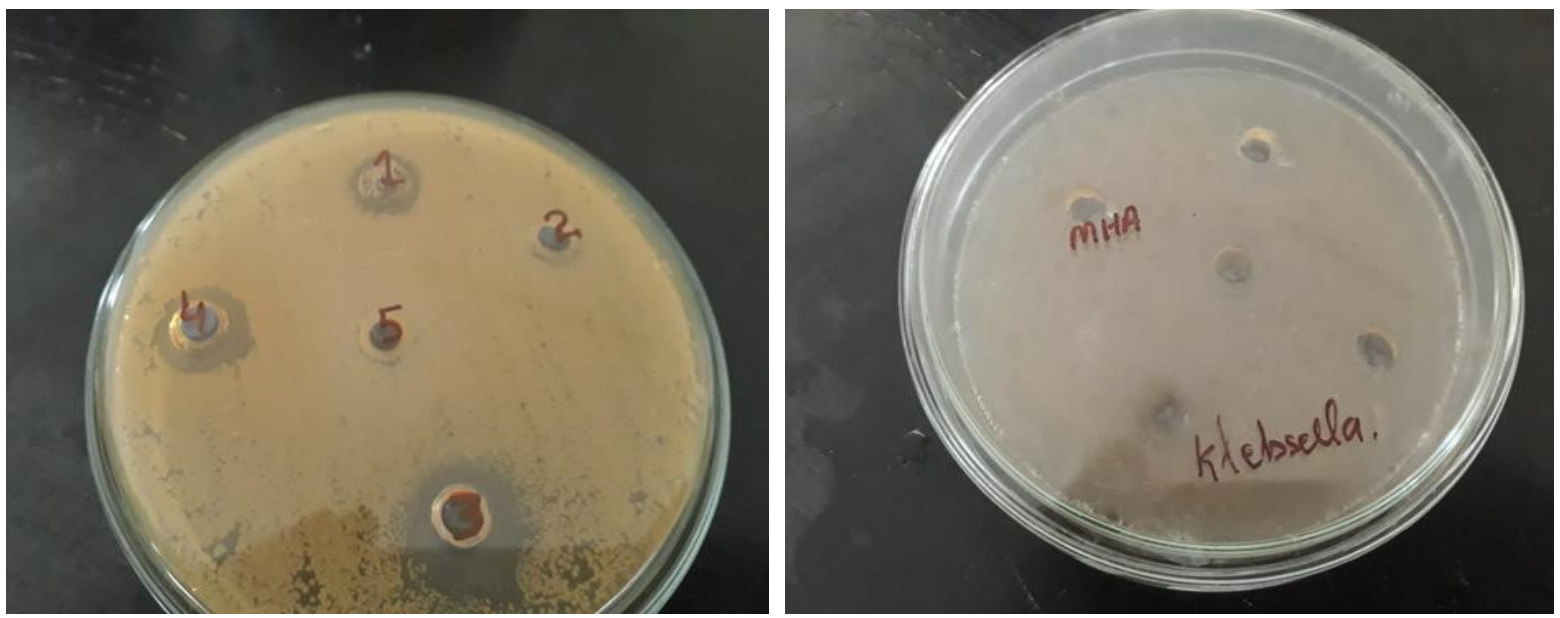

Figure 2. Antibacterial activity of N-methyl-o methoxybenzohroxamic acid and its metal complexes against Klebsiella
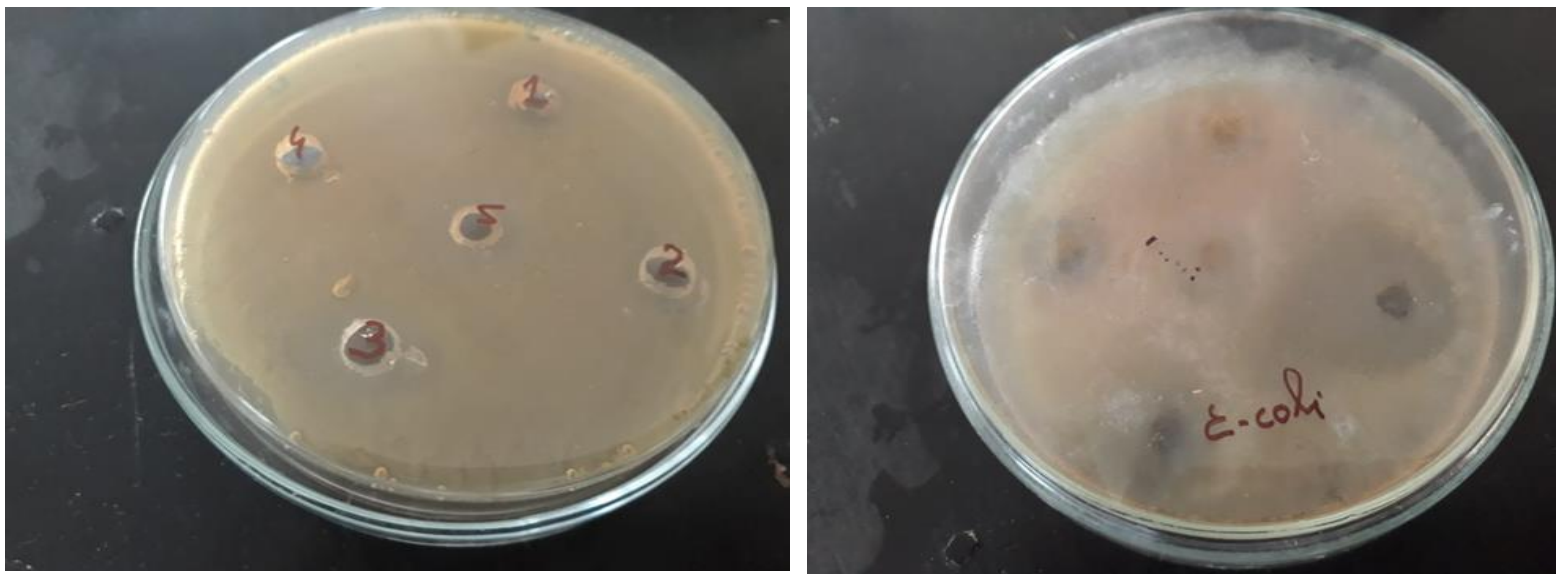

Figure 3. Antibacterial activity of N-methyl-o methoxybenzohroxamic acid and its metal complexes against $E$. coli
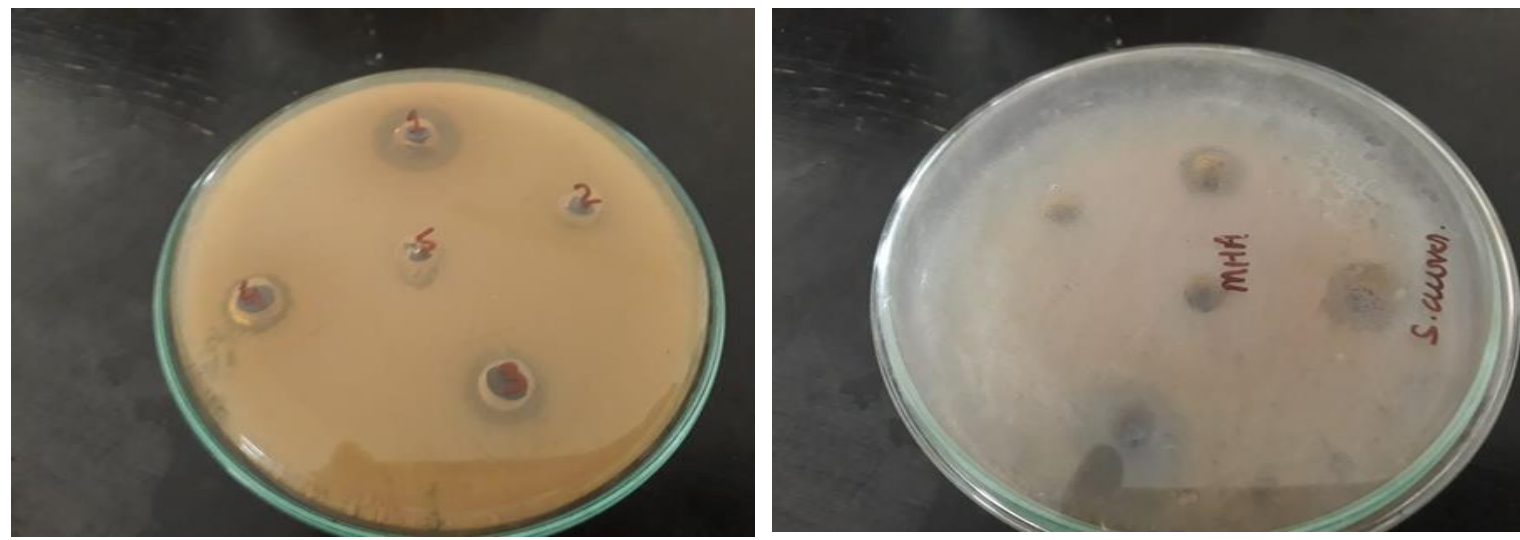

Figure 4. Antibacterial activity of N-methyl-o methoxybenzohroxamic acid and its metal complexes against S.aureus

\section{Conclusion}

The reportedly synthesized ligand and its freshly prepared transition metal complexes were carefully and successfully synthesized and characterized by FT-IR and UV/Vis spectroscopic techniques. The IR 
spectroscopic data indicates the complexation of ligands with the oxygen atom of the hydroxamic acid. The ligand and its complexes did not show any significant activity against fungal strains. The compounds can be used as antibacterial agents because of their higher activity and can be used for synthesizing new drugs for different illnesses because they showed positive activity against both gram-negative and gram-positive strains of bacteria.

\section{Authors' contributions}

Conceived and designed the experiments: Saifullah \& N Khan, Performed the experiments: Saifullah, I Ali, \& A Ghaffar, Analyzed the data: N Khan, Samiullah \& Saifullah Contributed materials/ analysis/tools: WA Shah \& Nizamuddin, Wrote the paper: Saifullah.

\section{References}

1. Irshad A, Khan N, Farina Y, Baloch N, Ali A, Mun LK \& Murtaza G (2018). Synthesis, spectroscopic characterization, $\mathrm{X}$-ray diffraction studies and in-vitro antibacterial activities of diorganotin (IV) derivatives with N-methyl-4bromobenzohydroxamic acid. Inorg Chim Acta 469: 280-287.

2. Thalluri K, Manne SR, Dev D \& Mandal B (2014). Ethyl 2-cyano-2-(4nitrophenylsulfonyloxyimino) acetatemediated Lossen rearrangement: singlepot racemization-free synthesis of hydroxamic acids and ureas from carboxylic acids. J Org Chem 79(9): 37653775.

3. Neilands JB (1967). Hydroxamic acids in nature. Sci 156(3781): 1443-1447.

4. Adiguzel E, Yilmaz F, Emirik M \& Ozil M (2017). Synthesis and characterization of two new hydroxamic acids derivatives and their metal complexes. An investigation on the keto/enol, E/Z and hydroxamate/hydroximate forms. $J \mathrm{Mol}$ Struct 1127: 403-412.

5. Sathiyavasan S, Sithambaresan M, Gunasingham P \& Srikaran R (2017). Synthesis and Spectroscopic Analysis of the Nature of Coordination Modes of Ligands in Copper (11) and Cadmium (11) Complexes of Two N-Oxidobenzamide Derivatives. Int J Sci Technol 5(5): 179.

6. Hassan LR, Ramasamy K, Lim SM, Bahron H \& Tajuddin AM (2018). Synthesis and characterization of benzohydroxamic acid metal complexes and their cytotoxicity study. $J$ Teknol 80(6).

7. Codd R (2008). Traversing the coordination chemistry and chemical biology of hydroxamic acids. Coordin Chem Rev 252(12-14): 1387-1408.

8. Carrott MJ, Fox OD, LeGurun G, Jones CJ, Mason C, Taylor R \& Boxall C (2008). Oxidation-reduction reactions of simple hydroxamic acids and plutonium (IV) ions in nitric acid. Radiochim Acta 96(6): 333-343.

9. Farkas E, Enyedy ÉA, Micera G \& Garribba E (2000). Coordination modes of hydroxamic acids in copper (II), nickel (II) and zinc (II) mixed-ligand complexes in aqueous solution. Polyhedron 19(14): 1727-1736.

10. Yilmaz F \& Yilmaz VT (2001). The Phthalhydroxamate Ligand and Its Divalent Transition Metal Complexes: Synthesis, Characterization, and Spectral and Thermal Studies. Syn React Inorg Met 31(8): 1421-1432.

11. Reddy AS, Kumar MS \& Reddy GR (2000). A convenient method for the preparation of hydroxamic acids. Tetrahedron Lett 41(33): 6285-6288.

12. Kakkar R, Dua A \& Zaidi S (2007). Preparation, properties and infrared spectral studies of $\mathrm{N}$-(p-ethylphenyl) thiobenzohydroxamic acid. Spectrochim Acta A 68(5): 1362-1369.

13. Valapour M, Guo J, Schroeder JT, Keen J, Cianferoni A, Casolaro V \& Georas SN (2002). Histone deacetylation inhibits IL4 gene expression in T cells. J Allergy Clin Immun 109(2): 238-245.

14. Mishra H, Parrill AL \& Williamson JS (2002). Three-dimensional quantitative structure-activity relationship and comparative molecular field analysis of dipeptide hydroxamic acid Helicobacter pylori urease inhibitors. Antimicrob Agents Ch 46(8): 2613-2618.

15. Giacomelli G, Porcheddu A \& Salaris, M (2003). Simple one-flask method for the preparation of hydroxamic acids. Org lett 5(15): 2715-2717.

16. Frezza M, Hindo S, Chen D, Davenport A, Schmitt S, Tomco D \& Ping DQ (2010). Novel metals and metal complexes as platforms for cancer therapy. Curr Pharm Design 16(16): 1813-1825. 
17. Rafique $\mathrm{S}$, Idrees $\mathrm{M}$, Nasim A, Akbar H \& Athar A (2010). Transition metal complexes as potential therapeutic agents. Biotechno Mol Biol 5(2): 38-45.

18. Warra AA (2011). Transition metal complexes and their application in drugs and cosmetics-a Review. J Chem Pharm Res 3(4): 951-958.

19. Fujimori T, Yamada S, Yasui H, Sakurai H, In Y \& Ishida T (2005). Orally active antioxidative copper (II) aspirinate: synthesis, structure characterization, superoxide scavenging activity, and in vitro and in vivo antioxidative evaluations. J Biol Inorg Chem 10(8): 831.

20. Baul TB, Masharing C, Ruisi G, Jirásko R, Holčapek M, de Vos D \& Linden A (2007). Self-assembly of extended Schiff base amino acetate skeletons, $2-\{[(2 Z)-(3-$ hydroxy-1-methyl-2-butenylidene)] amino $\}$ phenylpropionate and 2-\{[(E)-1(2-hydroxyaryl) alkylidene] amino phenylpropionate skeletons incorporating organotin (IV) moieties: Synthesis, spectroscopic characterization, crystal structures, and in vitro cytotoxic activity. $J$ Organomet Chem 692(22): 4849-4862.

21. Saad E, Farina Y, Baba I \& Othman H (2003). Synthesis and Characterization of Some Diorganotin bis (N-methyl Onitrobenzohydroxamate). Sains Malays 32: 79-86.

22. Temel H, Ilhan S, Kilic A \& Tas E (2008). Preparation and spectral characterization of new macrocyclic Ni (II) and Co (II) complexes derived from 1, 4-bis (2carboxyaldehydephenoxy) butane and various diamines. J Coordin Chem 61(9): 1443-1454.

23. Hope GA, Woods R, Parker GK, Buckley AN \& McLean J (2011). Spectroscopic characterisation of copper acetohydroxamate and copper noctanohydroxamate. Inorg Chim Acta 365(1): 65-70.

24. Sharma N, Kumari M, Kumar V, Chaudhry SC \& Kanwar SS (2010). Synthesis, characterization, and antimicrobial activity of oxovanadium (IV) hydroxamate complexes. J Coordin Chem 63(11): 1940-1950.

25. Raman N, Sakthivel A \& Rajasekaran K (2007). Synthesis and spectral characterization of antifungal sensitive
Schiff base transition metal complexes. Mycobiol 35(3): 150-153.

26. Anwar MM, Kalpana MA, Bhadra B, Rahman S, Sarker S, Chowdhury MH \& Rahmatullah M (2010). Antihyperglycemic activity and brine shrimp lethality studies on methanol extract of Cajanus cajan (L.) Millsp. leaves and roots. Adv Nat Appl Sci 4(3): 311-316.

27. Muri EM, Nieto MJ, Sindelar RD \& Williamson JS (2002). Hydroxamic acids as pharmacological agents. Curr Med Chem 9(17): 1631-1653.

28. Meyer BN, Ferrigni NR, Putnam JE, Jacobsen LB, Nichols DJ \& McLaughlin JL (1982). Brine shrimp: a convenient general bioassay for active plant constituents. Planta Med 45(05): 31-34.

29. Saliba LJ \& Krzyz RM (1976). Effect of heavy metals on hatching of brine-shrimp eggs. Mar Pollut Bull 7(10): 181-182.

30. Sarah QS, Anny FC \& Mir M (2017). Brine shrimp lethality assay. Bangladesh J Pharmac 12(2): 186-189.

31. Hossain MM, Ahamed SK, Dewanm S R, Hassan MM, Istiaq A, Islam MS \& Moghal MR (2014). In vivo antipyretic, antiemetic, in vitro membrane stabilization, antimicrobial, and cytotoxic activities of different extracts from Spilanthes paniculata leaves. Biol Res 47(1): 45.

32. Ahamad T, Kumar V, Parveen S \& Nishat N (2008). Synthesis, characterization and anti-microbial activity of poly (ethylene oxamide- $\mathrm{N}, \quad \mathrm{N}^{\prime}$-disuccinate) and its polymer metal complexes. $J$ Coordin Chem 61(9): 1423-1436.

33. Serbest K, Karaoğlu K, Erman M, Er M, \& Değirmencioğlu İ (2010). Synthesis, characterization and properties of tetra ((1hydroxyimino-methylnaphthalen-2-yloxy) methyl) ethene and its homo-dinuclear metal complexes. Spectrochim Acta A 77(3): 643-651.

34. Davis AL, Hulme KL, Wilson GT \& McCORD TJ (1978). In vitro antimicrobial activity of some cyclic hydroxamic acids and related lactams. Antimicrob Agents Ch 13(3): 542544 